\title{
Editorial
}

\section{Equity of access to primary care in the UK: is it likely to increase?}

Good access to health care exists when patients can get 'the right service at the right time in the right place' (Rogers et al., 1999). Thus, access depends not only on the availability of services in general, but on specific factors such as time (time waited for an appointment, and the length of time spent with a health care professional), geography (distance travelled to receive treatment) and financial resources (costs of travel, prescription charges, over-the-counter medicines). Furthermore, the way in which patients use services tend to reflect underlying aspects of their lives such as their socio-economic and educational status, their gender, age and ethnicity.

It is not surprising that the UK government is seeking to improve access in the hope that increased consumer satisfaction will ensure voter loyalty. However, such an attempt is likely to be in conflict with other policy imperatives such as cost containment. Improved access may simply increase demand. Is it desirable to increase demand for primary care among those who are already well-served and relatively healthy? For it is these people who are best at taking advantage of statutory services such as health care. Increasing demand for and access to health care is an important objective where services are underused, either because they are not available (e.g., inner-city areas which find it hard to attract GPs) or inappropriate to the needs of patients (e.g., in areas of ethnic and cultural diversity). In such cases, better access has an important role to play in reducing ill health, even though many of the key determinants of ill health are primarily socio-economic. For politicians, the tension between improving access in general (absolute access) and for deprived groups in particular (relative access) can be challenging. Is it fair to ask less well-off taxpayers to fund the greater convenience of services for those whose needs are least? Is it fair to ask better-off taxpayers to fund improved access which will not benefit themselves?

The NHS Plan includes strategies to improve access to primary care. These include policies to:

(i) to improve patient access by guaranteeing that patients can see a GP within 48 hours;

(ii) increase the numbers of GPs;

(iii) to provide alternatives to traditional primary care, such as walk-in centres and NHS Direct;

(iv) to make the best use of GPs by extending nurse roles (skill-mixing); and

(v) to increase the number of Personal Medical Services (PMS) sites as a way of targeting resources at underserved areas and/or population groups.

On the whole, it will be seen that the emphasis is on improving absolute access, although there is some recognition of the need for improving relative access. A recent review of interventions to improve access to primary care (Chapman et al., 2002) considered the evidence of both the intended and unintended impacts of 
new Government access initiatives.

The first two policies are primarily attempts to improve absolute access. However, the attempt to increase the number of GPs is also welcome from a relative access point of view. It will not in itself address relative access issues, but it is harder to redistribute human resources when these are in short supply in the first place.

New services such as NHS Direct and Walkin Centres are ways of providing alternatives to traditional primary care (iii), and are being widely used by patients. However, they appear to be more effective in improving absolute access, being used primarily by population groups who tend to use existing services, i.e., the white, healthy middle class. They are underused by older people, the chief users of NHS services. NHS Direct in particular is less likely to be used by people whose English is limited, by those with speech or hearing impairment, or by those without easy access to a telephone. These reservations apply to telephone consultations in traditional primary care too, although, like NHS Direct, they may increase access for those who find it hard to travel to the surgery because of disability, carer responsibilities or lack of transport. One might have expected that such initiatives would serve to free time for existing GPs, but so far there does not appear to be any clear reduction in the workload of other local service providers, though the rate of rising demand may have been slowed.

What are the implications for access of skill-mixing (iv)? This can be seen simply as increasing the capacity of GPs to concentrate on the tasks for which they are more qualified, and in that way enhance absolute access. Patients may welcome the longer consultations offered by nurses and therefore experience improved access. But substitution by nurses will be experienced as poorer access by patients who prefer to see their GP. Skill-mix is less feasible in single-GP practices, where teams are smaller, although patients of such practices tend to value continuity of care by their own GP, and would probably not welcome such change in any case.
It seems likely that extending PMS (v) can reduce inequalities in access: there is some evidence that some first-wave PMS pilots improved access to primary care in deprived areas or among deprived populations such as asylum-seekers (Jenkins et al., 2000). However, many first-wave PMS sites did not include improved access among their objectives, and evidence is lacking about subsequent waves.

It is important to remember that public policies other than those generated by the Department of Health and the NHS have key roles to play in supporting good access to health care. Improved public transport can improve physical access to services for those without private transport, economic regeneration in deprived areas and the provision of affordable housing in areas of prosperity can encourage primary care staff to live and work in underprovided areas. And much the best way of addressing relative access is to abolish poverty: reducing inequalities in the need for health care by reducing inequalities in health. From this point of view, the Treasury's intention to reduce poverty via the welfare benefits system may in the long run have more consequences for primary care access than anything the Department of Health does. The government's health policies are more concerned with absolute than with relative access, and are likely to be more successful in pleasing middle England than in addressing inequalities.

\section{Stephen Abbott, Research Fellow Public Health and Primary Care Unit City University, London, UK. Email:S.J.Abbott@ city.ac.uk}

\section{References}

Chapman, J., Carter, Y.H., Abbott, S., Bryar, R. and Congdon, P. 2002: Rapid review of access to primary care: a report to the Greater London Authority. London: Queen Mary's Department of General Practice and Primary Care, and City University, Public Health and Primary Care Unit. 
Jenkins, C., Lewis, R. and Gillam, S. 2000: Personal Medical Services pilots: two years on. British Journal of Health Care Management, 6, 12, 575-579.
Rogers, A., Flowers, J. and Pencheon, D. 1999: Improving access needs a whole systems approach and will be important in averting crises in the Millennium winter. BMJ, 319, 866-7. 